\title{
Psychological changes and improvement in chronic airflow limitation after corticosteroid treatment
}

\author{
DM MITCHELL, P GILDEH, M REHAHN, AH DIMOND, JV COLLINS
}

From Brompton Hospital, London, and Benenden Hospital, Benenden, Kent

ABSTRACT Corticosteroids may produce mood changes. This could account for improvement in patients with chronic airflow limitation following trials of oral corticosteroid treatment as mood + elevation might improve performance in objective measurements. This proposition was tested in $\cong$ 21 patients with chronic airflow limitation, who underwent detailed psychological assessment during a randomised controlled double blind crossover trial of the effect of prednisolone $40 \mathrm{mg}$ daily compared with that of a placebo. Self rating visual analogue scales for various qualities of mood were completed before the study and after each phase in addition to depression and psychological symptom questionnaires. After treatment with the placebo, patients showed increases in cheerfulness $(p<0.01)$ and sociability $(p<0.01)$ and a decrease in depression $(p$ $<0.01)$. After treatment with prednisolone there were increases in cheerfulness $(\mathrm{p}<0.01)$, optimism $(\mathrm{p}<0.01)$, activity $(\mathrm{p}<0.05)$, and sociability $(\mathrm{p}<0.02)$ and there was a decrease in depression $(\mathrm{p}<0.01)$. When placebo and prednisolone values were compared, however, there were no significant differences. Some patients showed improvements $(>20 \%)$ in peak expiratory flow, $\mathrm{FEV}_{1}$ or forced vital capacity (FVC) after prednisolone, but nearly all had improvements in at least one psychological test. There were no detectable associations between changes in objective measurements and changes in psychological test ratings. This study suggests that in patients with chronic obstructive lung disease significant psychological changes are no more likely to follow treatment with a corticosteroid than treatment with a placebo and that physiological improvement after corticosteroid treatment is not tied to psychological changes.

Progressive chronic airflow limitation is a common clinical problem and a short course of high dose corticosteroids is often tried when other measures fail to control progression of symptoms and disability. Many studies of the effects of treatment with oral corticosteroid drugs in patients with chronic airflow limitation have now been reported,' but the precise role of the treatment remains uncertain. Many studies have claimed demonstrable objective benefit from corticosteroids, ${ }^{2-6}$ although this is not universal. ${ }^{78}$ No previous study has examined the role of psychological changes in improvement following oral corticosteroid treatment.

It is well known, although difficult to prove conclusively, 9 that corticosteroids alter mood. Both mood elevation and depression may occur. The relationship between risk of frank psychosis and high

Address for reprint requests: Dr DM Mitchell, University College Hospital, London WC1E 6AU.

Accepted 29 June 1984 doses of oral corticosteroids is better established. ${ }^{10} \frac{\times}{x}$ It has been suggested" that the beneficial effect of 3 . corticosteroids in patients with chronic airflow limi- $\delta$ tation may not be the result of a genuine physiological improvement in pulmonary function, but couldo be due to a non-specific euphoriant effect that decreases the sensation of breathlessness and을 increases performance ability in objective tests.

In the present study a double blind randomised controlled crossover trial of the effect of pred- $N$ nisolone was carried out in patients with chronic airflow limitation. Detailed psychological assessments of mood were made to test the hypothesis that objective improvement following short courses of oral corticosteroids is linked to a euphoriant effecto of the drug.

\section{Methods}

We studied 21 patients (19 male) aged 50-77 (mean 924 
63) years. All had moderate to severe chronic airflow limitation with a mean $\mathrm{FEV}_{\mathrm{i}} / \mathrm{FVC}$ ratio of $43 \%$ ( $58 \%$ predicted). The mean forced expiratory volume in one second $\left(\mathrm{FEV}_{1}\right)$ was $1.021(36 \%$ predicted), forced vital capacity (FVC) 2.361 (62\% predicted), and total lung capacity (TLC) 7.41 ( $121 \%$ predicted). None of the patients had features suggesting asthma and all were in a stable condition during the study in that there had been no recent variation in breathlessness or infective exacerbation. All patients were receiving oral or inhaled $\beta_{2}$ adrenergic stimulants and some were also taking oral theophylline. The patients' usual treatment was not altered during the trial.

A double blind randomised crossover trial design was used to compare the effect of oral prednisolone $40 \mathrm{mg} /$ day for 14 days with visually identical placebo tablets for 14 days. The patients' consent was obtained. After a seven day run in period baseline measurements were obtained and treatment was started. After 14 days measurements were repeated and patients then received the alternative treatment for a further 14 days, when a final set of measurements was obtained. There was no interval between the two treatment phases. Eleven patients received placebo first and 10 received prednisolone first.

After the run in period and after each phase of treatment the following measurements were made. A subjective assessment of breathlessness was obtained by means of a simple breathlessness score (1-5) and the oxygen cost diagram..$^{12}$ Each patient completed a $10 \mathrm{~cm}$ visual analogue line self assessment rating for feelings of general well being. Arterial blood gases tensions were measured at rest. Exercise performance was assessed on the basis of the 12 minute walking distance,,$^{12}$ and a perceived exertion rating ${ }^{13}$ was obtained after the walk. Each patient did a practice walk several hours before the baseline 12 minute walk. Peak expiratory flow

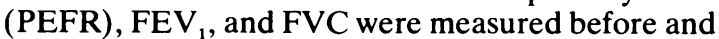
after inhalation of $200 \mu \mathrm{g}$ salbutamol aerosol. All measurements were made at the same time of day for each patient before routine bronchodilators had been taken. TLC was measured by body plethysmography.

The following psychological measurements were made. Mood was assessed by means of self rating 10 $\mathrm{cm}$ analogue lines ${ }^{14}$ recording separately cheerfulness, optimism, speed of thought, activity, and sociability. Scores of these five qualities were summed to produce a "euphoria rating." Analogue lines were also used to record sex drive, anxiety, and depression. Each patient completed the 20 item General Health Questionnaire, ${ }^{15}$ which is a screening assessment of current psychological symptoms, and the Wakefield self administered depression inventory. ${ }^{16}$ All tests were supervised by a physician who had received appropriate training in their administration. The physician made an assessment of mood after the run in period and after each phase on the basis of analogue lines recording depression, anxiety, and hypomania (speed of speech, hyperactivity, euphoric mood). Observations were analysed with the Wilcoxon matched pairs signed ranks test; identical results were obtained with Student's $t$ test. Unpaired observations were compared with the Mann-Whitney U test. Spearman's rank correlation coefficient was used to look for further associations.

\section{Results}

The effects of prednisolone and placebo are shown in table 1. Placebo treatment produced significant improvement in breathlessness, 12 minute walking distance, and PEFR. Similar changes from baseline values were seen after prednisolone treatment. When placebo values were compared with those recorded after prednisolone treatment, however, there were no significant differences detectable for any variable. Data from the 10 patients receiving prednisolone first and the 11 receiving placebo first were analysed separately. For no measurement were there more placebo responses in the group receiving

Table 1 Effect of prednisolone and placebo on mean symptom measurements and lung function values*

\begin{tabular}{|c|c|c|c|c|c|c|}
\hline & Baseline & $\begin{array}{l}\text { Baseline v } \\
\text { placebo }(P)\end{array}$ & Placebo & $\begin{array}{l}\text { Placebo v } \\
\text { prednisolone }\end{array}$ & Prednisolone & $\begin{array}{l}\text { Baseline v } \\
\text { prednisolone } \\
(P)\end{array}$ \\
\hline $\begin{array}{l}\text { Breathlessness score }(1-5) \\
\text { Oxygen cost diagram }(\mathrm{cm}) \\
\text { General wellbeing }(\mathrm{cm}) \\
\text { Distance walked in } 12 \mathrm{~min}(\mathrm{~m}) \\
\text { Perceived exertion (Borg) } \\
\text { Peak expiratory flow rate }\end{array}$ & $\begin{array}{l}3 \cdot 3 \\
5 \cdot 6 \\
6 \cdot 6 \\
904 \\
12\end{array}$ & $\begin{array}{l}<0 \cdot 01 \\
<0.05 \\
\text { NS } \\
<0 \cdot 001 \\
\text { NS }\end{array}$ & $\begin{array}{l}2 \cdot 8 \\
6 \cdot 2 \\
6 \cdot 9 \\
1020 \\
12\end{array}$ & $\begin{array}{l}\text { NS } \\
\text { NS } \\
\text { NS } \\
\text { NS } \\
\text { NS }\end{array}$ & $\begin{array}{l}2.7 \\
6.4 \\
7.6 \\
1037 \\
12\end{array}$ & $\begin{array}{l}<0.01 \\
<0.01 \\
\text { NS } \\
<0.001 \\
\text { NS }\end{array}$ \\
\hline $\begin{array}{l}\quad\left(1 \min ^{-1}\right) \\
\text { FEV }(1) \\
\text { Forced vital capacity (l) }\end{array}$ & $\begin{array}{l}211 \\
1 \cdot 02 \\
2 \cdot 36\end{array}$ & $\begin{array}{l}<0 \cdot 01 \\
\text { NS } \\
\text { NS }\end{array}$ & $\begin{array}{l}243 \\
1 \cdot 08 \\
2 \cdot 52\end{array}$ & $\begin{array}{l}\text { NS } \\
\text { NS } \\
\text { NS }\end{array}$ & $\begin{array}{l}246 \\
1 \cdot 15 \\
2 \cdot 68\end{array}$ & $\begin{array}{l}<0.01 \\
<0.05 \\
<0.01\end{array}$ \\
\hline
\end{tabular}

*Wilcoxon matched pairs signed ranks test used to compare means.

NS- not significant. 
Table 2 Effect of prednisolone and placebo on mean values in psychological tests*

\begin{tabular}{|c|c|c|c|c|c|c|}
\hline $\begin{array}{l}\text { Analogue lines } \\
(0-10 \mathrm{~cm})\end{array}$ & Baseline & $\begin{array}{l}\text { Baseline v } \\
\text { placebo } \\
(P)\end{array}$ & Placebo & $\begin{array}{l}\text { Placebo } v \\
\text { prednisolone }\end{array}$ & Prednisolone & $\begin{array}{l}\text { Baseline v } \\
\text { prednisolone } \\
(P)\end{array}$ \\
\hline $\begin{array}{l}\text { Cheerfulness } \\
\text { Optimism } \\
\text { Speed of thought } \\
\text { Activity } \\
\text { Sociability } \\
\text { Sum = euphoria rating }\end{array}$ & $\begin{array}{r}5 \cdot 8 \\
5 \cdot 6 \\
6 \cdot 3 \\
5 \cdot 3 \\
6 \cdot 8 \\
29 \cdot 4\end{array}$ & $\begin{array}{l}<0.01 \\
\text { NS } \\
\text { NS } \\
\text { NS } \\
<0.01 \\
\mathrm{p}<0.05\end{array}$ & $\begin{array}{r}7 \cdot 3 \\
6 \cdot 6 \\
7 \cdot 1 \\
6 \cdot 0 \\
7 \cdot 7 \\
34 \cdot 8\end{array}$ & $\begin{array}{l}\text { NS } \\
\text { NS } \\
\text { NS } \\
\text { NS } \\
\text { NS } \\
\text { NS }\end{array}$ & $\begin{array}{r}7 \cdot 6 \\
7 \cdot 1 \\
7 \cdot 2 \\
6 \cdot 5 \\
7 \cdot 8 \\
36 \cdot 3\end{array}$ & $\begin{array}{l}<0.01 \\
<0.01 \\
\text { NS } \\
<0.05 \\
<0.02 \\
\text { p }<0.01\end{array}$ \\
\hline $\begin{array}{l}\text { Sex }(\mathrm{cm}) \\
\text { Depression }(\mathrm{cm}) \\
\text { Anxiety }(\mathrm{cm}) \\
\text { General Health }\end{array}$ & $\begin{array}{l}2 \cdot 6 \\
3 \cdot 1 \\
2 \cdot 9\end{array}$ & $\begin{array}{l}\text { NS } \\
<0 \cdot 01 \\
\text { NS }\end{array}$ & $\begin{array}{l}2 \cdot 6 \\
1 \cdot 7 \\
2 \cdot 1\end{array}$ & $\begin{array}{l}\text { NS } \\
\text { NS } \\
\text { NS }\end{array}$ & $\begin{array}{l}2 \cdot 6 \\
2 \cdot 0 \\
2 \cdot 1\end{array}$ & $\begin{array}{l}\text { NS } \\
\text { NS } \\
\text { NS }\end{array}$ \\
\hline $\begin{array}{l}\text { Questionnaire }(0-20) \\
\text { Wakefield Depression } \\
\text { Inventory }(0-32)\end{array}$ & $\begin{array}{r}3 \cdot 5 \\
11 \cdot 8\end{array}$ & $\begin{array}{l}\text { NS } \\
<0.01\end{array}$ & $\begin{array}{l}1 \cdot 8 \\
7 \cdot 7\end{array}$ & $\begin{array}{l}\text { NS } \\
\text { NS }\end{array}$ & $\begin{array}{l}1 \cdot 8 \\
7 \cdot 7\end{array}$ & $\begin{array}{l}<0.05 \\
<0.01\end{array}$ \\
\hline
\end{tabular}

*Wilcoxon matched pairs signed ranks test used to compare means. NS-not significant.

placebo after prednisolone, so that a carry over effect is unlikely. The effect of prednisolone and placebo on psychological state is shown in table 2 . There was significant elevation of mood after treatment with placebo. The changes comprised increased cheerfulness, increased sociability, and decreased depression. After treatment with prednisolone similar changes from the baseline state were seen. No significant differences were observed for any variable when placebo values were compared with prednisolone values, suggesting that prednisolone had no euphoriant effect over and above that of placebo. Eight of the 21 patients were depressed according to the Wakefield questionnaire after the run in period; the number fell to three after placebo and two after prednisolone treatment. Ten patients had a positive score on the General Health Questionnaire and this number fell to four after placebo and two after prednisolone. The only significant change in the doctor's ratings of psychological state was a significant fall in anxiety after both placebo and prednisolone.

Correlation coefficients were calculated for all pairings of psychological measurements after the run in period and both treatment phases. There were strong positive correlations $(p<0.01-<0.001)$ between positive self ratings for mood qualities on the one hand and lack of depression and psychological symptoms on the other. There were also strong correlations between placebo values and prednisolone values, indicating that individuals rated themselves similarly after both treatments. Correlation coefficients were determined between psychological measurements and objective measurements to look for possible associations between psychological state before the study and the severity of symptoms and disability, but no significant correlations were found. Similarly, there was no cor- relation between baseline psychological state and $\overparen{\varnothing}$ objective improvement after prednisolone.

Finally, patients were divided into those with a greater than $20 \%$ improvement in PEFR, FEV ${ }_{1}$ or FVC (or all three) and those without such improve- $\infty$ ment after either placebo or prednisolone. The + results of all psychological measurements of the responder and of the non-responder groups were then compared (Mann-Whitney $U$ test). No significant differences in score for any psychological test were found between the two groups; thus no $\mathbb{Q}$ association between individual response and $\vec{\overrightarrow{ }}$ psychological change could be established. No individual became overtly depressed or hypomanic during treatment with prednisolone.

\section{Discussion}

There was considerable improvement in both subjective and objective measurements after treatment 3 . with placebo. Although most patients were admitted to hospital for the study, any improvement due simply to hospital admission was circumvented by a oneo week run in period before baseline values were obtained. The placebo effect moreover was shown not to be due to steroid "carry over." Furthermore ${ }^{17}$ the mean maximum peak flow rate is known ${ }^{\circ}$ to occur eight days after starting treatment with pre- $N$ dnisolone in patients with chronic airflow obstruc-N tion, and that the hypothalamic-pituitary-adrenalo axis returns to normal within three days of stopping prednisolone $(40 \mathrm{mg} /$ day $) ;{ }^{18}$ it is therefore unlikely that a beneficial effect due to steroids would persist? until placebo measurements were taken 14 dayst after cessation of steroid treatment. Even if theo strong placebo response was partially due to the fact that this study was carried out in inpatients, this isi itself important as it is common practice to admit 
patients with chronic airflow limitation for a trial of steroid treatment. Possibly such trials should include a placebo phase.

The practical problem posed by a trial of steroids in chronic airflow limitation arises where there is no objective response to treatment yet the patient claims substantial benefit. A subjective improvement without objective change may be regarded with suspicion by the physician as being purely due to a euphoriant effect of steroids." $A$ single objective measurement such as PEFR or FEV may, however, be misleading as the patient's subjective assessment has been shown to correlate with 12 minute walking distance and FVC rather than $\mathrm{FEV}_{1}{ }^{19}$

It is well known that corticosteroid treatment may produce psychological changes, ${ }^{9}$ particularly in doses of greater than $40 \mathrm{mg}$ prednisolone a day. ${ }^{10}$ Nevertheless, in a large controlled study of patients taking corticosteroids $(20 \mathrm{mg}$ or less of prednisolone/day) for various respiratory diseases there was no increased incidence of psychosis in the treated group. ${ }^{20} \mathrm{~A}$ recent study ${ }^{21}$ of 39 patients with neuromuscular disorders having corticosteroid treatment showed that they had less emotional disorder than a well matched group of 33 similar patients attending the same clinic who were not having such treatment. This might support the view that corticosteroids are euphoriant, but no measure of euphoria was made.

In the present study it could be argued that psychological changes were not seen because of the small number of patients studied. We feel, however, that if the commonly observed improvement in chronic airflow limitation with steroid treatment is due to the euphoriant effect there should have been more improvement in the prednisolone group in this study as some patients did improve physiologically.

Our study has shown that there is no correlation between psychological state and severity of disability or treatment response. A considerable placebo benefit was seen both in objective measurements and in psychological state. Prednisolone had no effect on psychological state over and above the placebo effect. We conclude that steroids do not produce benefit in chronic airflow limitation by a non-specific euphoriant effect.

We would like to thank staff members of the physiotherapy and pulmonary function departments at Brompton Hospital and Benenden Hospital for their assistance. We would also like to thank Dr PJ Noble, Maudsley Hospital, for help and advice with psychological measurements, and Dr F Moss and Dr $P$ Nunn for help with data collection.

\section{References}

1 Sahn SA. Corticosteroids in chronic bronchitis and pulmonary emphysema. Chest 1978;73:389-96.

2 Clifton M, Stuart-Harris $\mathrm{CH}$. Steroid therapy in chronic bronchitis. Lancet 1962;i:1311-3.

3 Harding SM, Freedman S. A comparison of oral and inhaled steroids in patients with chronic airways obstruction: features determining response. Thorax 1978;33:214-8.

4 Shim C, Stover DE, Williams MM. Response to corticosteroids in chronic bronchitis. $J$ Allergy Clin Immunol 1978;62:363-7.

5 Mendella LA, Manfreda J, Warren CPW, Anthonisen NR. Steroid response in stable chronic obstructive pulmonary disease. Ann Intern Med 1982;96:17-21.

6 Lam WK, So SY, Yu DYL. Response to oral corticosteroids in chronic airflow obstruction. $\mathrm{Br} J$ Dis Chest 1983;77:189-98.

7 Evans JA, Morrison IM, Saunders KB. A controlled trial of Prednisolone, in low dosage, in patients with chronic airways obstruction. Thorax 1974;29:401-6.

8 Stokes TC, Shaylor JM, O' Reilly JF, Harrison BDW. Assessment of steroid responsiveness in patients with chronic airflow obstruction. Lancet 1982;ii:345-8.

9 Ling MHM, Perry PJ, Tsuang MT. Side effects of corticosteroid therapy. Arch Gen Psychiatry 1981;38:471-7.

10 Boston Collaborative Drug Surveillance Program. Acute adverse reactions to Prednisolone in relation to dosage. Clin Pharmacol Ther 1972;13:694-8.

11 . Freedman BJ. Bronchodilators and corticosteroids in chronic bronchitis and emphysema. $\mathrm{Br} \mathrm{Med} J$ 1963;ii:1509-12.

12 McGavin CR, Artivini M, Maoe H, McHardy GJR. Dyspnoea, disability and distance walked: comparison of estimates of exercise performance in respiratory disease. Br Med J 1978;ii:241-3.

13 Borg G. Perceived exertion as an indicator of somatic stress. Scand J Rehab Med 1970;2-3:92-8.

14 Aitken RCB. Measurement of feelings using analogue scales. Proc R Soc Med 1969;62:989-92.

15 Goldberg DP. The detection of psychiatric illness by questionnaire. Maudsley Monograph 21. 1972 Oxford University Press, Oxford.

16 Snaith RP, Ahmed SN, Mehta S, Hamilton M. Assessment of the severity of primary depressive illness. Wakefield self-assessment depression inventory. Psychological Medicine 1971;1:143-9.

17 Webb J, Clark TJH, Chilvers C. Time course of response to Prednisolone in chronic airflow obstruction. Thorax 1981;36:18-21.

18 Webb J, Clark TJH. Recovery of plasma corticotrophin and cortisol levels after a 3 week course of Prednisolone. Thorax 1981;36:22-4.

19 Williams IP, McGavin CR. Corticosteroids in chronic airways obstruction: Can the patient's assessment be ignored? Br J Dis Chest 1980;74:142-8.

20 Smyllie HC, Connolly CK. Incidence of serious complications of corticosteroid therapy in respiratory disease. Thorax 1968;23:571-81.

21 Cordess C, Folstein M, Drachman D: Psychiatric effects of alternate day steroid therapy. Brit J Psychiat 1981;138:504-6. 